\title{
Disease profiles of detainees in the Canton of Vaud in Switzerland: gender and age differences in substance abuse, mental health and chronic health conditions
}

Karine Moschetti ${ }^{1,2,8^{*}}$, Pierre Stadelmann ${ }^{1,8}$, Tenzin Wangmo ${ }^{3}$, Alberto Holly ${ }^{4}$, Patrick Bodenmann ${ }^{5}$, Jean-Blaise Wasserfallen², Bernice S. Elger ${ }^{3,7}$ and Bruno Gravier ${ }^{6}$

\begin{abstract}
Background: Literature on the disease profile of prisoners that differentiates by age and gender remains sparse. This study aimed to describe the health of correctional inmates in terms of substance abuse problems and mental and somatic health conditions, and compare it by gender and age.

Methods: This study examined cross-sectional data from the Canton of Vaud in Switzerland on the health conditions of detainees who were in prison on January 1, 2011 or entered prison in 2011. Health conditions validated by physician examination were reported using the International Classification of Diseases (ICD) version 10. The analyses were descriptive by groups of prisoners: the entire sample (All), Men, Older adults and Women.

Results: A total of 1,664 individuals were included in the analysis. Men comprised $91.5 \%$ of the sample and had a mean age of 33 years. The other $8.5 \%$ were women and had an average age of 39. Older adults (i.e., age 50 and older) represented $7 \%$ of the total sample. Overall, $80 \%$ of inmates were non-Swiss citizens, but the proportion of Swiss prisoners was higher among the older adults (51\%) and women (29\%). Overall, $41 \%$ of inmates self-reported substance abuse problems. Of those, $27 \%$ were being treated by psychiatrists for behavioral disorders related to substance abuse. Chronic infectious diseases were found in $9 \%$ of the prison population. In addition, $27 \%$ of detainees suffered from serious mental health conditions. Gender and age had an influence on the disease profile of this sample: compared to the entire prison population, the older inmates were less likely to misuse illegal drugs and to suffer from communicable infections but exhibited more problems with alcohol and a higher burden of chronic health conditions. Female prisoners were more disposed to mental health problems (including drug abuse) and infectious diseases. In terms of chronic diseases, women suffered from the same conditions as men, but the diseases were more prevalent in women.
\end{abstract}

Conclusion: It is important to understand the different disease profiles of prisoners by gender and age, as it helps identify the needs of different groups and tailor age-and gender-specific interventions.

\footnotetext{
* Correspondence: karine.moschetti@chuv.ch

'Institut universitaire de médecine sociale et préventive, Unité d'evaluation des soins, University Hospital of Lausanne (CHUV), Route de la Corniche 10, 1010 Lausanne, Switzerland

${ }^{2}$ Technology Assessment Unit (UET), University Hospital of Lausanne (CHUV), Lausanne 1011, Switzerland

Full list of author information is available at the end of the article
}

\section{Biomed Central}

(c) 2015 Moschetti et al. Open Access This article is distributed under the terms of the Creative Commons Attribution 4.0 International License (http://creativecommons.org/licenses/by/4.0/), which permits unrestricted use, distribution, and reproduction in any medium, provided you give appropriate credit to the original author(s) and the source, provide a link to the Creative Commons license, and indicate if changes were made. The Creative Commons Public Domain Dedication waiver (http://creativecommons.org/publicdomain/zero/1.0/) applies to the data made available in this article, unless otherwise stated. 


\section{Background}

The prison population is increasing worldwide [1], and it is widely accepted that prison inmates have poor health due to accumulated vulnerability factors such as traumatic life experiences, lack of a social network and low socioeconomic background [2]. Studies have shown that poly-morbidity among prisoners is high, with substance abuse, mental illnesses and infectious diseases as the most common health problems [3-5]. Substance abuse and dependence are common problems encountered among the prison population [6,7]. It is not uncommon to observe 1 out of 3 or even 1 out of 2 inmates with drug abuse or dependence [8]. Smoking and alcohol problems are also common in prisons [9-11]. The widely-known negative health outcomes of tobacco use and secondhand smoke are highly problematic, and even more so in confined environments $[12,13]$.

Psychotic and personality disorders, including antisocial personality problems and major depression, are often identified among incarcerated people [14]. A recent literature review conducted in 24 countries revealed a constant prevalence of psychotic disorders over time [15]. Although they have conflicting figures, empirical studies on psychiatric and psychological disorders among young prisoners have confirmed the high prevalence of mental health problems [16].

With regard to prisoners' physical health, there have been extensive investigations into infectious diseases such as human immunodeficiency virus and acquired immunodeficiency syndrome (HIV), hepatitis B and C and tuberculosis [5, 17]. Although there is still some uncertainty about the actual number of people living behind bars with these communicable illnesses, studies have consistently reported prevalence rates exceeding those observed in the community $[18,19]$. In high income countries, the prevalence of HIV and tuberculosis has been found to be about 10 to15 times higher than in the civilian population [3, 20]. Moreover, the extent of infectious-disease transmission within prisons remains unknown; it is, however, not marginal $[18,21]$.

By comparison, non-infectious diseases have received less attention [19], and studies describing specific chronic conditions and their frequencies among offenders are limited. Available data highlight higher rates of diabetes, hypertension and asthma among inmates when compared to the general population in the USA [22], whereas in Switzerland the prevalence of these conditions among the prison population has been in line with that of the general population [3].

Most of the abovementioned studies present health information for young male prisoners, who form the bulk of the prison population (more than $90 \%$ in most countries) [23]. Knowledge about the health status of special groups is limited. However, the number of older adults in prison is growing and is projected to increase further [24]. The growing older prisoner population is even viewed as a future health and economic crisis for both criminal justice systems and societies [25]. Today, in many countries, there is a tendency towards longer custodial sentences and sentences of undetermined length and/or life sentences, meaning that people entering prison when they are young are likely to remain when they are older [26]. Defining a strict threshold for when a prisoner becomes an "older prisoner" is complicated [27]. Prison contributes to accelerating the biological process of aging, and time spent in prison aggravates and increases medical problems [28]. Few papers in the literature tackle the health issues of this still small proportion of the prison population [26]. Reviews have suggested that prisoners aged 55 and older have a much higher prevalence of major diseases and functional impairments and multi-morbidity than younger prisoners [5] and non-prisoners of similar age [5, 26]. However, little is known about the extent to which chronic and degenerative diseases linked to aging - whose physiological signs (in the community) include hearing, visual and cognitive decline as well as reduced mobility -will increase the healthcare needs of older prisoners [29].

Women are another minority group in prison. They make up less than $8 \%$ of the total prison population in Europe by country [23]. Like older prisoners, their population is reported to be growing. Explanations of this growth include a combination of social and political factors [30] linked to the nature of the offences committed. The majority of women are incarcerated for non-violent, property or drug-related crimes, for which they generally serve short sentences [31]. Like their male counterparts, or even more so, incarcerated women are disproportionately affected by multiple health problems such as substance abuse (DAPHNE Projects data in MacDonald, 2013), HIV infection, sexually transmitted diseases and severe mental health problems [8, 32]. Furthermore, post-traumatic disorders, depression, self-harming behaviors and eating disorders are also common among female inmates [31, 32].

Limited research has been done on prisoners' health and disease profile (including non-infectious, chronic diseases) that differentiates between these specific groups. In particular, there are very few studies in which the health problems among male, female and older prisoners have been estimated for the same prison setting/ area and over the same time period. And yet, better knowledge of the epidemiological situation in prison particularly the extent to which health is similar or different among male, female and older prisoners - is a prerequisite for evaluating prisoners' healthcare needs and determining how to provide appropriate and targeted 
health services. This study examines exhaustive and recent health and demographic data on prisoners living in the Canton of Vaud, which is a region in the French-speaking part of Switzerland. The aim is to portray the health of correctional inmates, including their somatic and mental health conditions and substance abuse, and to differentiate by gender and age.

\section{Methods}

In 2011, the prison population in Switzerland amounted to around 6,100 inmates distributed across111 institutions [33]. With about 80 prisoners per 100,000 inhabitants, Switzerland has one of the lowest incarceration rates in the world [34]. The present work reports data from the entire prison population of the Canton of Vaud. Approximately 1 in 10 permanent Swiss residents lives in the Canton of Vaud. It has one semi-open prison and 4 closed facilities for both men and women. The five institutions receive remand prisoners and prisoners serving sentences (see Table 1). The total number of stays in prison rose from 1,941 in 2002 to 2,610 in 2011.

The study used an exhaustive and unique dataset of demographics and medical information for all the prisoners in the closed facilities in 2011. It includes prisoners who were already in prison on January 1, 2011 and those who entered these facilities at any time throughout 2011. Cross-sectional data for the 2,610 inmate stays were individually collected by the Service of Correctional Medicine and Psychiatry (Service de Médecine et Psychiatrie Pénitentiaire-SMPP) affiliated with the University Hospital of Lausanne (CHUV). After data management, data cleaning and collapsing the multiple stays by the same individual over the 12 months into a single stay, the final sample consisted of 2,185 individuals. The study sample was then restricted to individuals who had a routine physician examination upon prison entry $(N=1,664)$. Under Swiss law, every incarcerated person should be seen by a general practitioner (GP) within 7 to 21 days following his/her entry [35, 36]. There may have been individuals who refused the entry examination. Also, time constraints such as a short stay or transfer to another prison may not have allowed for a

Table 1 The four closed facilities in the Canton of Vaud

\begin{tabular}{lcll}
\hline Prison's name & Capacity & Type of sentences served & $\begin{array}{l}\text { Gender of } \\
\text { inmates }\end{array}$ \\
\hline $\begin{array}{l}\text { Bois Mermet } \\
\text { La Tuilière }\end{array}$ & 100 & $\begin{array}{l}\text { Custody on remand } \\
\text { Remand (men + women) } \\
\text { and custodial sentences } \\
\text { (women) }\end{array}$ & $\begin{array}{l}\text { Male } \\
\text { Male and } \\
\text { female }\end{array}$ \\
La Croisée & 170 & $\begin{array}{l}\text { Remand and short custodial } \\
\text { sentences }\end{array}$ & Male \\
Plaine de l'Orbe & 264 & Long sentences & Male \\
\hline
\end{tabular}

meeting with a GP. Because the health information for these prisoners $(n=521)$ was incomplete, their data was removed from our analysis. All new prisoners receive a health evaluation by a nurse within $24 \mathrm{~h}$ of their entry in order to manage emergency situations and ensure continuity of care. In addition to the examinations by the GP and nurse, $44.8 \%(N=747)$ of the prisoners were examined by a psychiatrist and were found as having at least one psychiatric health conditions. The number of prisoners examined by a psychiatrist and without psychiatric diagnosis is negligible. Psychiatric examination happens at the request of health professionals (GP, nurses), penitentiary staff or the prisoners themselves. The psychiatric examination may also be a compulsory part of the prisoners' sentence.

Thus, the information on inmates' health conditions came from diagnoses made by a GP for somatic problems and by a psychiatrist for mental problems. These diagnoses relied on the prisoners' case history, their selfreported information and additional medical tests when necessary. Health conditions were reported using the International Classification of Diseases (ICD) version 10, from which chronic diseases were selected and further examined. ICD-10 is the standard diagnostic tool for routine medical practice and epidemiology. It is used to monitor the incidence and prevalence of diseases and other health problems [37]. Moreover, using ICD-10 to report health conditions is imperative for psychiatry, since it is the only classification accepted for health- and disability-insurance purposes in Switzerland. We also used information from nurses' consultations regarding inmates' substance-related problems. In such cases, two complementary assessments for these disorders are available: that nurse's assessment containing the inmate's self-declarations, and the psychiatrist's diagnosis.

Based on ICD-10, chronic conditions related to infections, skin problems, and the musculoskeletal, digestive, circulatory, endocrine, respiratory and nervous systems were sorted into groups. Additional subgroups were also created, including back pain, hypertension, diabetes, asthma, bronchitis, and migraines. For the purposes of our study, 4 prisoner groups were looked at: the entire study sample (All), men, older adults and women. Although the threshold for "older" prisoners varied from 50 to 65 years depending on the study [5, 27], we chose to define older adults as people aged 50 or older.

\section{Statistical analysis}

The analyses were descriptive for each prisoner group: the entire sample (All), men, older adults and women. Statistical analyses included percentages, means, and standard deviations (SDs) or $95 \%$ confidence intervals (CI). We used a Chi-squared test to explore associations between diseases and patients' characteristics. Logistic 
regression models, including age and gender as adjustment variables, were run to test potential origin of related diseases. Statistical analyses were performed with STATA, the Data Analysis and Statistical software (version 12, StataCorp).

\section{Ethical considerations}

The study was approved by the ethical commission of the Canton of Vaud, Switzerland (Protocol No. 388/12). Data were anonymized. As the study was retrospective and used only anonymized and aggregated data, individual agreement was not required.

\section{Results}

\section{Socio-demographic characteristics}

A total of 1,664 individuals examined by a physician upon entry were included in our analysis. The study sample was similar to the whole sample $(N=2,185)$ in terms of gender, age and nationality. The 521 individuals (24 \%) who were excluded had stayed an average of 16 days, suggesting that they were released or transferred before the GP examination. Men comprised $91.5 \%$ of the study sample, and their mean age was 32.8 years (SD 10.3, range 16-82 years). Women represented $8.5 \%$ of the sample population and had an average age of 38.8 (SD 10.3, range 16-69 years). Older adults (aged $50+)$ made up $7 \%$ of the sample $(n=136)$ and averaged 57.02 years old (SD (6.07, range 50-82 years). Among the older group, $90 \%$ were men. Other demographic characteristics such as age group, marital status and nationality for the 3 study groups are provided in Table 2.

From the sample population, $80 \%$ of inmates were non-Swiss citizens, but the proportion of Swiss detainees was higher among the older adults (51\%) and women (29\%). Nationalities of 99 different countries were reported, with the main regions being Eastern Europe and Africa for the full sample, Western Europe for the older adults, and Africa and Eastern Europe for the women (Table 2).

Eleven percent of all prisoners had entered prison prior to 2010 ( $28 \%$ of the older adults and $23 \%$ of the women). Most of the prison population entered prison during the study year (62\%). Among them, $22 \%$ had stays of less than one month, and $73 \%$ of less than 6 months.

Comparing the characteristics of our sample with the prison population of Switzerland for the same year (see Table 2), our study sample showed the same proportion of men and women and a similar age distribution, but the Swiss nationality was less represented. There were also differences in the length of stays: in 2011, stays lasting less than one month amounted to $22 \%$ in our sample compared with more than double that nationally. On the other hand, $27 \%$ of detainees in the Canton of Vaud had a stay longer than 6 months, versus $20 \%$ nationally. The proportion of prisoners in the sample serving long sentences was higher than in the national prison population. This may be related to the presence of facilities for long custodial sentences in the Canton of Vaud that are not necessarily available in all Swiss prisons.

\section{Disease profile of the prisoners (All)}

Prisoners suffered from multiple health problems, as reported in Tables 3 and 4 . Overall, $41 \%$ of inmates selfdeclared substance-abuse problems, such as with illegal drugs, pharmaceuticals or alcohol. Of that group, $27 \%$ were being treated by psychiatrists for behavioral disorders related to psychoactive substance use (Table 3). Psychiatric examination also revealed evidence of psychiatric problems other than substance abuse. The prevalence of personality and behavioral disorders among inmates was $16.2 \%$, and $15.9 \%$ for neurotic disorders. Prisoners also suffered from schizophrenia, mood disorders and behavioral syndromes. Overall, $35.1 \%$ suffered from some form of mental disorder other than substance use.

Chronic infectious diseases were found in $9 \%$ of the prison population. Hepatitis C and HIV were the most common. In terms of somatic chronic health problems, the most frequently identified diseases were those affecting the musculoskeletal system (13\%). Other problems are detailed in Table 4. In addition, almost 1 prisoner in 2 self-reported smoking. Among all prisoners, $40 \%$ had at least one somatic chronic health condition.

\section{Older adults}

A lower rate of mental illness related to psychoactive substance use and confirmed by a psychiatrist was found among older inmates compared to prisoners under 50 (19 \% vs. $27 \%$ ). Notably, compared to prisoners under 50 , older adults were significantly less likely to misuse illegal drugs $(p<0.0001)$ but more likely to abuse alcohol $(p<0.0001)$. Self-reported information on substance use was $30 \%-45 \%$ higher than what was confirmed by psychiatric follow-up. In all, $3.5 \%$ of the older prisoners had the 3 dependencies.

Data indicated that $42.6 \%$ of the older inmates suffered from at least one psychiatric disorder other than substance use. Twenty-six percent suffered from personality disorders, $13 \%$ from neurosis, $6.6 \%$ from schizophrenia and $4 \%$ from mood disorders.

Of the older adults, $1.5 \%$ were found to have HIV and $3 \%$ to have hepatitis $C$. There was no significant difference compared to prisoners under $50(p=0.35$ and $p=0.23)$. 
Table 2 Demographic characteristics, year of entry and length of prison stay for the prison population in the Canton of Vaud and in all of Switzerland for 2011

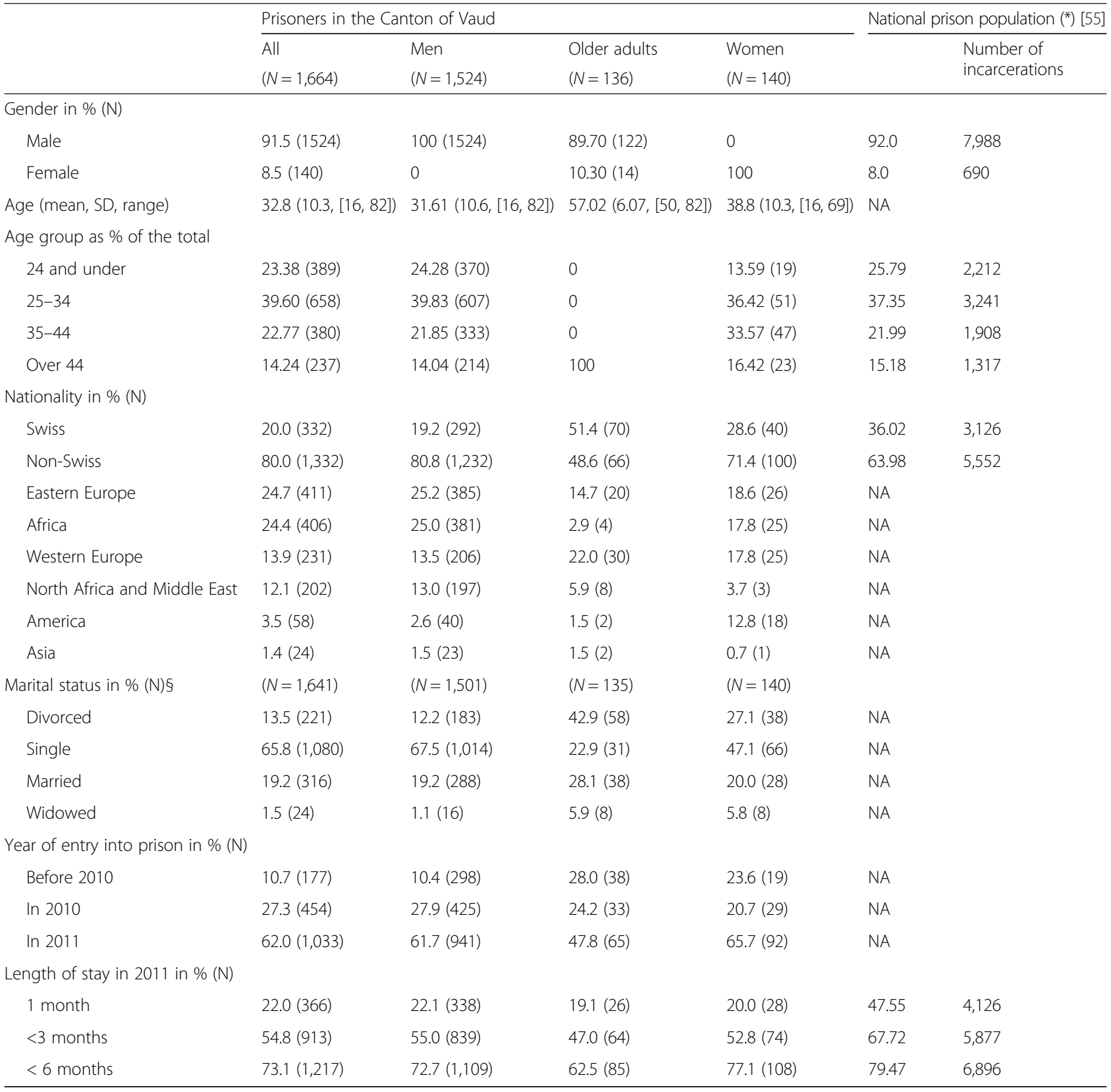

${ }^{*}$ ) Characteristics of the national prison population refer to the number of incarcerations and not to the number of individuals NA: Information not available

(§) This information is missing for 23 observations

Diseases of the musculoskeletal, circulatory and respiratory systems were more frequent in the group of older adults than in the full sample. The association between being an older adult and suffering from a health condition was statistically significant for back pain $(p=0.02)$, hypertension $(p<0.0001)$, bronchitis $(p=0.002)$ and endocrine disorders $(p<0.0001)$ and almost statistically significant for digestive problems ( $p=0.058)$. Overall, $60 \%$ of older prisoners had at least one chronic health condition (excluding mental problems).

\section{Women}

Female inmates had a higher prevalence of psychiatric problems than the men. Behavioral disorders related to psychoactive substance use were confirmed by a specialist to exist in one-third of the female detainees, significantly higher than in the men. Female inmates were more often found to have drug addictions (26\% vs. $17.2 \%, p=0.013)$. However, no gender differences were evident for misuse of pharmaceuticals ( $4.2 \%$ for women vs. $5.3 \%$ for men) or alcohol (10.7 \% for women $v s 9.4 \%$ 
Table 3 Mental health conditions and dependencies for the four groups

\begin{tabular}{|c|c|c|c|c|c|c|c|c|c|c|}
\hline \multirow[t]{2}{*}{$\begin{array}{l}\text { Proportion of prisoners with a mental illness (ICD } 10 \text { codes) } \\
\text { and psychiatric follow-up }\end{array}$} & \multicolumn{2}{|c|}{$\begin{array}{l}\text { All } \\
(N=1664)\end{array}$} & \multicolumn{2}{|c|}{$\begin{array}{l}\text { Men } \\
(N=1524)\end{array}$} & \multicolumn{2}{|c|}{$\begin{array}{l}\text { Older adults } \\
(N=136)\end{array}$} & \multicolumn{2}{|c|}{$\begin{array}{l}\text { Women } \\
(N=140)\end{array}$} & \multicolumn{2}{|l|}{$\begin{array}{l}\text { Chi } 2 \\
p \text {-value }\end{array}$} \\
\hline & $\%$ & $95 \% \mathrm{Cl}$ & $\%$ & $95 \% \mathrm{Cl}$ & $\%$ & $95 \% \mathrm{Cl}$ & $\%$ & $95 \% \mathrm{Cl}$ & Sex & Age \\
\hline $\begin{array}{l}\text { Mental illness classified as a behavioral disorder due to } \\
\text { psychoactive substance use (F10-F19) }\end{array}$ & 26.3 & $24.2-28.4$ & 25.6 & $23.4-27.9$ & 19.1 & $12.8-26.7$ & 32.8 & $25.1-41.3$ & NS & 0.048 \\
\hline Drugs (F11-12-13-19) & 18.0 & $16.1-19.9$ & 17.2 & $15.4-19.2$ & 3.7 & $1.2-8.4$ & 25.7 & $18.7-33.8$ & 0.013 & $<0.001$ \\
\hline Pharmaceuticals (F13) & 5.2 & $4.2-6.4$ & 5.3 & $4.2-6.6$ & 2.2 & $0.4-6.3$ & 4.2 & $1.6-9.0$ & NS & NS \\
\hline Alcohol (F10) & 9.5 & $8.0-11.1$ & 9.4 & 8.0-11.0 & 16.2 & $10.4-23.4$ & 10.7 & $6.1-17.0$ & NS & 0.006 \\
\hline Schizophrenia (F 20-F29) & 5.3 & $4.3-6.5$ & 5.1 & $4.0-6.3$ & 6.6 & $3.0-12.2$ & 7.1 & $3.5-12.8$ & NS & NS \\
\hline Mood [affective] disorders (F30-F39) & 2.2 & $1.6-3.1$ & 1.7 & $1.1-2.4$ & 3.7 & $1.2-8.4$ & 7.8 & 4.0-13.6 & $<0.001$ & NS \\
\hline $\begin{array}{l}\text { Neurotic, stress-related and somatoform disorders } \\
\text { (F40-F49) = mainly reaction to severe stress, and } \\
\text { adjustment disorders }\end{array}$ & 15.9 & $14.1-17.8$ & 14.8 & $13.0-16.7$ & 13.2 & $8.0-20.1$ & 27.1 & 19.9-35.3 & $<0.001$ & NS \\
\hline $\begin{array}{l}\text { Behavioral syndromes associated with physiological } \\
\text { disturbances and physical factors (F50-F59) }\end{array}$ & 1.9 & $1.3-2.7$ & 1.9 & $1.3-2.7$ & 0.0 & 0.0 & 1.4 & $0.2-5.0$ & NS & NS \\
\hline Disorders of adult personality and behavior (F60-69) & 16.2 & $14.5-18.0$ & 15.1 & $13.3-16.9$ & 25.7 & $18.6-34.0$ & 27.8 & $20.6-36.0$ & $<0.001$ & $<0.002$ \\
\hline Mental retardation (F70-79) and other disorders (F80-99) & 2.8 & $2.0-3.6$ & 2.5 & $1.8-3.5$ & 3.7 & $1.2-8.4$ & 5.0 & $2.0-10.0$ & NS & NS \\
\hline Any mental disorder (excluding substance use) & 35.1 & $32.8-37.5$ & 33.3 & $31.0-35.7$ & 42.6 & $34.2-51.4$ & 55.0 & $46.3-63.4$ & $<0.001$ & 0.050 \\
\hline
\end{tabular}

NS: not significant (at a $5 \%$ level)

for men). In examining the self-declared substance abuse assessments, pharmaceutical misuse was significantly more frequently reported by women than men (16 \% vs. $10 \% ; p=0.024)$. A large proportion (40\%) of female inmates reported smoking.

Regarding other mental disorders, results showed that female prisoners were more disposed to mental illnesses than men, with the increased prevalence ranging from $25 \%$ to $75 \%$. The only exception was behavioral syndromes, for which the rate was slightly lower than for men (1.5\% vs. $2 \%)$. Moreover, there was a significant gender difference for 3 groups of mental disorders: mood disorders, "reaction to severe stress" and personality disorders (see Table 3).

Among the various infectious diseases, HIV and hepatitis $C$ infections were significantly more frequent among female prisoners than male prisoners (9.2 vs. $2.7 \% p<0.0001$ for HIV and $10 \%$ vs. $5.2 \%$ $p=0.002$ for hepatitis C). However, less than $1 \%$ had hepatitis B (no gender difference found). Back pain, hypertension, asthma and migraines were more frequent among female than male inmates. While back pain and hypertension didn't show a significant gender difference, asthma and migraines did (5\% vs. $2.3 \% p=0$. 03; resp. $4.2 \%$ vs. $0.7 \% p<0.0001)$.

\section{Chronic diseases related to origin in the study sample}

Compared to people from Western Europe (including Swiss people), prisoners from Africa and Eastern Europe were less likely to suffer from substance abuse (OR 0.11 95 \% CI 0.07-0.16 and OR 0.27 95 \% CI 0.19-0.37), but those from the Middle East were more likely (OR 1.71
$95 \%$ CI 1.23-2.39), particularly with pharmaceutical (OR $7.7095 \%$ CI 4.50-13.17) and alcohol (OR 2.04 95 \% CI 1.32-3.15) dependencies. Lower prevalence rates for alcohol misuse were found in Eastern European (OR 0.41 $95 \%$ CI 0.25-0.69) and African inmates (OR $0.3095 \%$ CI0.16-0.54) compared with Western European prisoners. Detainees from the Middle East had a higher burden of digestive disorders (OR 2.20, 95 \% CI 1.24-3.89), prisoners from Africa more frequently reported hypertension (OR 2.43, $95 \%$ CI 1.22-4.85) than prisoners from Western Europe, but less frequently endocrine disorders (OR 0.4195 \% CI 0.16-1.04; $p=0.062$ ).

\section{Discussion}

Using a cross-sectional, large-scale and comprehensive dataset on prisoner health, this study portrayed the epidemiological situation of the prison population in the Canton of Vaud, Switzerland. First, unlike other studies that use prison population samples, this study analyzed exhaustive data on prisoners in Vaud Canton over the same time period. Second, while many studies tend to emphasize either male prisoners or young prisoners, we differentiated the disease profiles between groups of inmates (All, Men, Older adults and Women). Third, this study provides direct comparisons between the health of two minority inmate groups (older adults and women) and the younger and male prisoners on four aspects of health: substance abuse, mental health, infectious diseases and chronic conditions. As such, it contributes to the literature on the health burden among prisoners in general, and that of older and female prisoners in particular. Finally, this study underlines the fact that 
Table 4 Main chronic health conditions of the 4 groups

\begin{tabular}{|c|c|c|c|c|c|c|c|c|c|c|c|}
\hline \multirow[t]{2}{*}{$\begin{array}{l}\text { Proportion of prisoners with diseases } \\
\text { (ICD } 10 \text { codes) }\end{array}$} & \multicolumn{2}{|c|}{$\begin{array}{l}\text { All } \\
(N=1664)\end{array}$} & \multicolumn{2}{|c|}{$\begin{array}{l}\text { Men } \\
(N=1524)\end{array}$} & \multicolumn{2}{|c|}{$\begin{array}{l}\text { Older adults } \\
(N=136)\end{array}$} & \multicolumn{2}{|c|}{$\begin{array}{l}\text { Women } \\
(N=140)\end{array}$} & \multicolumn{2}{|l|}{$\begin{array}{l}\text { Chi } 2 \\
\text { P-value }\end{array}$} & \multirow{2}{*}{$\begin{array}{l}\text { Prevalence data in the } \\
\text { general Swiss population } \\
\%\end{array}$} \\
\hline & $\%$ & $95 \% \mathrm{Cl}$ & $\%$ & $95 \% \mathrm{Cl}$ & $\%$ & $95 \% \mathrm{Cl}$ & $\%$ & $95 \% \mathrm{Cl}$ & Sex & Age & \\
\hline Infectious diseases & 8.9 & $7.6-10.4$ & 8.1 & $6.8-9.6$ & 4.4 & $1.6-9.3$ & 17.1 & $11.3-24.4$ & $<0.001$ & NS & \\
\hline HIV (B20-B24-Z21) & 2.7 & $1.9-3.6$ & 2.1 & $1.1-2.9$ & 1.5 & $0.1-5.2$ & 9.0 & $5.0-15.3$ & $<0.001$ & NS & $0.3[56]$ \\
\hline Hepatitis B (B16 B18) & 1.5 & $1.0-2.2$ & 1.6 & $1.0-2.3$ & 0.0 & $0-2.6$ & 0.7 & $0.01-3.9$ & NS & NS & $0.3[57]$ \\
\hline Hepatitis C (B17 B18.2) & 5.0 & $4.1-6.2$ & 4.6 & $3.6-5.6$ & 2.9 & $0.8-7.3$ & 10.7 & $6.1-17.0$ & 0.002 & NS & $0.7-1[57]$ \\
\hline Tuberculosis (A15 A16) & 0.36 & $0.13-0.78$ & 0.4 & $0.08-0.7$ & 0.0 & & 0.0 & & NS & NS & $0.007[56]$ \\
\hline Tuberculosis sequelae (B90) & 0.66 & $0.33-1.17$ & 0.7 & $0.3-1.1$ & 0.0 & & 0.0 & & & & \\
\hline $\begin{array}{l}\text { Diseases of the musculoskeletal } \\
\text { system (M10 M15 M54 M54.4) }\end{array}$ & 12.8 & $11.2-14.5$ & 12.8 & $11.1-14.5$ & 21.3 & $14.7-29.2$ & 12.8 & 7.8-19.5 & NS & 0.002 & \\
\hline Back pain only (M54 M54.4) & 9.0 & $7.8-10-6$ & 9.0 & 7.6-10.6 & 14.7 & $9.2-21.8$ & 10.7 & $6.1-17.0$ & NS & 0.020 & $\begin{array}{l}8.8 \text { for } 34<\text { age }<44 ; 11.9 \\
\text { for } 55<\text { age }<64[58]\end{array}$ \\
\hline $\begin{array}{l}\text { Diseases of the digestive system } \\
\text { (K21 K25-K } 26 \text { K29 K58 K70) }\end{array}$ & 7.6 & $6.4-9.0$ & 7.6 & $6.4-9.1$ & 11.7 & $6.9-18.4$ & 7.1 & $3.4-12.7$ & NS & NS & \\
\hline $\begin{array}{l}\text { Diseases of the circulatory system } \\
\text { (I05-109 I10 I20 I25 I50 187.2) }\end{array}$ & 6.5 & $5.4-7.8$ & 6.3 & $5.2-7.7$ & 33.0 & $25.2-41.6$ & 7.8 & $4.0-13.62$ & NS & $<0.001$ & \\
\hline Hypertension (I10) & 5.5 & $4.3-6.6$ & 5.3 & $4.2-6.5$ & 25.7 & $18.6-33.9$ & 6.4 & $2.9-11.8$ & NS & $<0.001$ & $\begin{array}{l}2.2-8.1 \text { for age }<49 ; 23.6 \\
\text { for } 50<\text { age }<64[59]\end{array}$ \\
\hline $\begin{array}{l}\text { Skin problems (B36.0 D10-D36 } \\
\text { L20-30 L40 L50 L70) }\end{array}$ & 8.1 & $6.8-9.5$ & 8.3 & $6.9-9.8$ & 5.8 & $2.5-11.2$ & 5.7 & $2.5-11$ & NS & NS & \\
\hline Endocrine diseases (E66 E10-14 E78) & 5.1 & $4.1-6.2$ & 5.2 & $4.1-6.4$ & 22.8 & $16.0-30.7$ & 4.3 & $15.9-9.1$ & NS & $<0.001$ & \\
\hline Diabetes (E10-14) & 2.1 & $1.5-2.9$ & 2.1 & $1.5-3.0$ & 13.23 & $8.0-20.1$ & 2.1 & $0.4-6.1$ & NS & $<0.001$ & $\begin{array}{l}0.6-1.8 \text { for age }<49 ; 5.8 \\
\text { for } 50<\text { age }<64[59]\end{array}$ \\
\hline $\begin{array}{l}\text { Diseases of the respiratory system } \\
\text { (J30 J32 J41 J45) }\end{array}$ & 5.5 & $4.4-6.7$ & 5.4 & $4.3-6.6$ & 9.5 & $5.2-15.8$ & 6.4 & $3-11.9$ & NS & 0.029 & \\
\hline Asthma (J45) & 2.3 & $1.7-3.2$ & 2.1 & $1.4-2.9$ & 2.9 & $0.8-7.3$ & 5.0 & $2.0-10.0$ & 0.030 & NS & 2.5 for age $30-39$ yrs [60] \\
\hline Bronchitis (J41) & 2.1 & $1.5-2.9$ & 2.2 & $1.5-3.1$ & 5.9 & $2.5-11.2$ & 1.4 & $0.1-5.0$ & NS & 0.002 & \\
\hline $\begin{array}{l}\text { Diseases of the nervous system } \\
\text { (G40 G43.0) }\end{array}$ & 1.4 & $0.9-2.0$ & 1.1 & $0.6-1.8$ & 2.2 & $0.4-6.3$ & 4.2 & $1.5-9$ & 0.002 & NS & \\
\hline Migraines (G43.0) & 0.7 & $0.3-1.2$ & 0.4 & $0.1-0.8$ & 0.7 & $0.1-4.0$ & 4.2 & $1.5-9.0$ & $<0.001$ & NS & $\begin{array}{l}7.7 \text { for age }<24-9.3 \\
\text { for age }<44[58]\end{array}$ \\
\hline \multicolumn{12}{|l|}{$\begin{array}{l}\text { Self-reported subs. misuse or } \\
\text { dependence }\end{array}$} \\
\hline Drug misuse & 32.2 & $29.6-34.5$ & 32.0 & $29.6-34.3$ & 5.9 & $2.5-11.2$ & 35.0 & $27.1-43.5$ & NS & $<0.001$ & $\begin{array}{l}\text { Cannabis: men 12; } \\
\text { women } 415<\text { age < } 34 \\
{[61]}\end{array}$ \\
\hline Pharmaceutical misuse & 10.8 & $9.3-12.3$ & 10.2 & $8.7-11.7$ & 4.0 & $1.6-9.3$ & 16.0 & $10.7-23.6$ & 0.024 & 0.013 & \\
\hline Alcohol misuse & 18.9 & $17.0-20.8$ & 19.0 & $16.9-20.9$ & 24.2 & $17.3-32.5$ & 17.8 & $11.9-25.2$ & NS & NS & \\
\hline Cigarette misuse & 46.4 & $43.9-48.8$ & 46.9 & $44.4-49.4$ & 38.9 & $30.7-47.7$ & 40.0 & $31.8-48.6$ & NS & & $\begin{array}{l}28.2 \% \text { in } 2012 \text { [59]; } 32.4 \\
\text { for men; } 24.2 \text { for women; }\end{array}$ \\
\hline $\begin{array}{l}\text { Any drug, pharmaceutical, } \\
\text { or alcohol misuse }\end{array}$ & 40.8 & $38.4-43.1$ & 40.7 & $38.2-43.2$ & 29.4 & $21.9-37.8$ & 42.1 & $33.8-50.7$ & NS & 0.005 & \\
\hline
\end{tabular}

NS: not significant (at a $5 \%$ level)

prisoners are suffering from multiple morbidities combining psychiatric and somatic disorders. Beyond these findings, our study also made some specific and important points, which are highlighted below.

From the literature, it is evident that prisoners are at higher risk for drug problems than those living in the community $[5,6]$. There is a notable heterogeneity among studies, and estimated prevalence of drug abuse varies from $10 \%$ to $53 \%$ in male offenders. In a Swiss context, active use of illegal drugs was found in $40 \%$ of remand prisoners [3]. In our study, the two available measures on drug problems revealed differences: $18 \%$ of prisoners were diagnosed with drug abuse problems in the psychiatric follow-up, but in the entry examination 
conducted by nurses, $32 \%$ of inmates self-declared being active drug users. The difference can be explained by 3 factors. The main explanation is that many detainees declared themselves to be drug abusers even when not addicted and without necessarily having or showing symptoms requiring a psychiatrist examination. If such prisoners do not explicitly seek psychiatric help to treat their drug misuse problem, they are not seen by psychiatrists. Also, the estimated rate from self-reports may be overestimated. Some prisoners may report problems for the purpose of obtaining medications/treatments that would help them bear incarceration [21]. Finally, the organizational constraints of incarceration may imply that some prisoners do not have time or opportunity to see a psychiatrist during their stay. The number of prisoners with a psychiatric diagnosis of substance use may thus be underestimated, especially for men, given their greater numbers. The heterogeneity of data on substance abuse in prison underscores the challenge of obtaining an accurate prevalence of drug use/misuse in the prison population [38], especially when some prisoners hide their dependencies to avoid sanctions [21].

Our findings indicate that the need for substance abuse treatment is great and important for inmates. It is also now recognized that systematically rehabilitating prisoners with substance abuse problems often remains an empty hope [39]. Previous therapy consisting of providing drug-free programs have now been replaced by substitution -methadone-maintenance programs -at least in some European countries [40]. This has been the therapeutic approach adopted in the prisons included in this study for several years.

Communicable diseases, such as hepatitis B and C and HIV were found at rates between 5 and 10 times greater than those reported in the Swiss general population (Table 3). Our results are consistent with those in France and Canada [20, 41, 42] and those found in the large remand Swiss prison in Geneva [3]. With a rate of tuberculosis among the studied inmates $>50$ times that of Swiss civilians, our findings confirm the public health issues related to this disease. As pointed out by the WHO (Stop TB Strategy [43]), the prison population is one of the risk groups that needs special attention. Efforts already implemented to improve detention conditions (including overcrowding, hygiene conditions and nutrition) should be further developed to better contain the transmission of this disease. This is particularly relevant in a population made up of a disproportionate number of individuals with high risk factors for tuberculosis (HIV, intravenous drug use, low socioeconomic background as well as geographical origin [43]).

The prevalence of common conditions such as back pain, hypertension, diabetes and asthma among prisoners was in the same range as that observed in their counterparts living outside the prison in the country (Table 4). Compared to recent US studies, prisoners from the Canton of Vaud tended to show lower rates of hypertension, asthma and diabetes [8]. Moreover, compared to a publication reporting health problems among detainees in Geneva [3], our results exhibited lower rates of skin problems, migraines and asthma, but higher rates of back pain, diabetes and hypertension. There are several explanations to account for these differences. First, our study sample was older, which may explain the higher rate of hypertension and diabetes. Second, instead of focusing on remand prisoners, our sample included inmates not only on remand awaiting trial, but also on trial and serving short and long sentences. Prisoners serving sentences have to work in prison under sometimes sub-optimal or not very ergonomic conditions, leading to health problems such as back pain. Third and importantly, the methodology differed in that the health conditions of prisoners were reported according to 2 different international classifications: International Classification of Primary Care versus ICD-10.

Compared to the entire study population, the older adult prisoners showed a different disease profile. First, older prisoners did not suffer from the same type of addictions. Drug abuse was significantly less frequent among prisoners aged 50+, whereas alcohol abuse disorders were more frequent. This finding is in line with results from Scottish prisoners where the group aged 40-64 showed a higher proportion of prisoners with alcohol dependence than the group aged 25-39 [9]. Additionally, a recent analysis of the health profile of older prisoners in north-west England revealed that the prevalence of alcohol abuse was higher than that of drug abuse [26]. A second feature of the disease profile of the older adults was the higher prevalence of mental disorders compared to their younger counterparts. Excluding the dependence disorders, about $40 \%$ of older prisoners had mental health problems. In our study, schizophrenia was reported at $6.5 \%$ and personality disorders at $26 \%$, while the English study found rates of $5 \%$ and $20 \%$ respectively [26]. Third, communicable infections were significantly less frequent among older prisoners than younger prisoners. Finally, older prisoners showed a higher prevalence of more common chronic diseases than their younger counterparts, and than older people living outside the prison. Overall, these findings confirmed the previous results indicating that a large proportion of older prisoners suffer from psychiatric illnesses and chronic health problems $[44,45]$. The differences in disease profiles between younger and older prisoners raise questions about the required healthcare needs of prisoners, not only now but also in the future.

In prison, healthcare needs linked to aging have emerged as great challenges. Addressing the delivery of 
healthcare services to older prisoners with multiple morbidities as well as age-related degenerative diseases raises inescapable issues with respect to the equivalence of care between prison and the community [46]. Provision of equivalent care takes on an extra dimension with the management of cognitive impairments such as dementia [47] and transitional end-of-life care needs [48]. Another issue that impacts the health of older prisoners is the structural environment of prison facilities. The prisons were initially designed for vigorous and independent people, and were not built to provide decent care to people who might need assistance with basic personal everyday life tasks and/or who may have geriatric syndromes.

Gender also had an influence on the disease profile among the study population. We found that substance abuse was more often encountered in female than in male prisoners. Our results reinforced previous findings showing gender differences in the prevalence of drug use disorders among prisoners [6, 8]. In Europe, previous studies have found problematic drug use ranging from $10 \%$ to $50 \%$ in female prisoners [49]. Up-to-date results based on DAPHNE Projects data and reported by McDonald [30] revealed that $75 \%$ of female prisoners in Germany, and 98 \% in Scotland, had addiction problems with drugs, alcohol, prescription drugs and eating disorders. We also found that female prisoners were more likely than men to have co-existing psychiatric disorders such as personality disorders, depression and anxiety. This is in line with results reported in the literature $[50,51]$ showing that women were also more likely to self-harm and commit suicide than male inmates [32]. In addition, although it was not examined in our study due to a lack of available data, many female prisoners might also be mothers or have worries about children. As a result, the mental health needs of female prisoners are complex.

Stress and anxiety associated with incarceration may be compounded by the overcrowded conditions and violence existing in prison facilities. If overcrowding significantly worsens the physical health of prisoners by encouraging the spread of communicable disease, it seems likely that overcrowding could also adversely impact the mental health of prisoners [52]. Mental illness also complicates treatment for co-morbidities, such as HIV, which requires strict adherence to drug therapy and careful monitoring for adverse drug interactions [53]. Addressing the mental health needs of male and female prisoners will improve not only their quality of life but also that of the prison staff and those without mental health illnesses [54].

Compared to men, women in prison had a higher burden of communicable diseases (almost double), especially for HIV and hepatitis C. This is similar to estimations from French prisons [20]. As for common chronic diseases, the incarcerated women in the study region suffered from the same health conditions as men but the diseases were more prevalent in women. Additionally, female prisoners have specific needs related to reproductive health (menstruation, menopause, pregnancy), and such needs are often more challenging than those of men [30,51]. The growing number of incarcerated women raises concerns about gender-specific issues and needs in places initially designed for men.

\section{Limitations and strengths}

The aim of this study was to describe the health status of prisoners by investigating substance abuse and mental health and chronic health problems, including infectious diseases. The study provides much needed knowledge on health in prison and helps to identify prisoners' specific healthcare needs in general as well as by age and gender. However, our decision to focus on chronic conditions does not allow us to provide a complete picture of health problems since daily illnesses and symptoms (injuries) were excluded. Special focus on these more acute disorders would be interesting. Errors in collecting and reporting data may exist even if several checks were carried out to ensure coherence. Having restricted the analysis to people who were examined upon entry limited the underestimation errors of not only infectious and communicable diseases, but also chronic diseases. Indeed, the examination upon entry as a routine provides a detailed medical history of the prisoners and as such may identify symptoms leading to a precise diagnosis. Although examination on entry might also help identify other problems that individuals arrive with and that are associated with life experience, they may be more difficult to categorize. Concerning whether the data can be generalized, we analyzed the characteristics of those prisoners who did not receive a physician entry visit and were removed from our results. We found that they were similar to those included in the study in terms of gender, nationality and marital status. The excluded group was slightly younger (mean age of 30 years, $\mathrm{SD}=9.5$ ). Their average length of stay was 16 days. We have concluded that excluding these individuals has very little impact on the data and does not prevent the results from being generalized. Finally, it cannot be excluded that the prevalence of psychiatric disorders might be slightly underestimated since not all prisoners had the opportunity to have a psychiatric examination. This is because their stay was short or because they were transferred to another prison in Switzerland (or they were deported to their country of origin). However, this was a very small proportion of the prisoners 
since specific training for both nurses and penitentiary staff allows them to identify psychiatric needs efficiently. They are therefore able to set up an examination relatively quickly. More than $95 \%$ of new prisoners are seen by nurses, assuring good medical follow-up/management. Thus the percentage of inmates in need of a psychiatric examination who do not get the opportunity is very small indeed and has little impact on the data.

Strengths of this study include the large sample size and use of recent, exhaustive data from a prison population. This population includes different types of inmates, ranging from prisoners on remand awaiting trial to prisoners serving a sentence. Thus it closely mirrors the prison population of all of Switzerland, thereby increasing its external validity and allowing for extrapolation of our results.

\section{Conclusion}

This paper contributes to the knowledge on disease profiles of incarcerated persons with a particular focus on two minority groups- older inmates and female inmates- on which the literature remains sparse. The specificities of their health situations help identify priorities for group-specific interventions. There is an urgent need for research priorities and policy initiatives on "aging and health" in the criminal justice system. Devising them will be beneficial both for the inmates and prison health professionals, who may feel powerless without the specific knowledge to deal with this group. Also, it seems crucial to evaluate the extent to which the aging prison population will be taxing on societies in terms of financial and other resources. Programs already in place that appropriately target female inmates should be sustained and, where possible, reinforced. More longitudinal research investigating health trends over time and health prior to and during detention are also needed. Such work would allow us to determine the changes that occur in the health profile of prisoners upon incarceration as well as the extent to which health of prisoners deteriorates or improves in prison, and the factors associated with those health changes.

\section{Abbreviations \\ ICD: International Classification of Disease; GP: General practitioner; Cl: Confidence interval; OR: Odds ratio; SD: Standard deviation.}

\section{Competing interests}

The authors declare that they have no competing interests.

\section{Authors' contributions}

KM is responsible for the study design, and interpreted the data, supported data management, conducted the statistical analysis, and drafted the manuscript. PS performed data management and conducted the statistical analysis. TW made substantial contributions to improve the study design. AH participated in the initial conception of the work. PB participated in the interpretation of the data. JBW made substantial contributions to improve the study design. BE participated in the initial conception of the work. BG elaborated and coordinated data collection and participated in the interpretation of the data; he revised the intellectual content of the manuscript. All authors gave critical contributions to the manuscript. They also approved the final version.

\section{Acknowledgements}

The authors would like to thank staff of the Service of Correctional Medicine and Psychiatry (SMPP) for the efforts in collecting the data.

This research was undertaken as part of a larger project funded by the Swiss National Science Foundation (SNF) and thus the authors acknowledge the financial support received from the SNF (CR1311_135035/1).

\section{Author details}

${ }^{1}$ Institut universitaire de médecine sociale et préventive, Unité d'evaluation des soins, University Hospital of Lausanne (CHUV), Route de la Corniche 10,

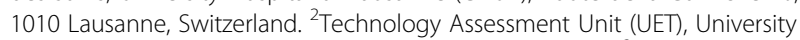
Hospital of Lausanne (CHUV), Lausanne 1011, Switzerland. ${ }^{3}$ Institute for Biomedical Ethics, Institute for Biomedical Ethics, University of Basel, Bernoullistrasse 28, Basel 4056, Switzerland. ${ }^{4}$ Institut d'économie et management de la santé (IEMS), HEC Lausanne and Département d'économétrie et d'économie politique (DEEP), University of Lausanne, Internef Building, Lausanne 1015, Switzerland. ${ }^{5}$ Vulnerable Population Center, Department of Ambulatory Care and Community Medicine, University of Lausanne, Lausanne 1011, Switzerland. 'Service of Correctional Medicine and Psychiatry (SMPP), University Hospital of Lausanne (CHUV), Prilly-Lausanne 1008, Switzerland. ${ }^{7}$ Centre universitaire romand de médecine légale, University of Geneva, Geneva, Switzerland. ${ }^{8}$ IEMS - Plateforme interfacultaire en économie et management de la santé, University of Lausanne $\mathrm{CH}$, Internef Building, Lausanne 1015, Switzerland.

Received: 1 July 2014 Accepted: 2 September 2015

Published online: 10 September 2015

\section{References}

1. Justice M. Story of the Prison Population: 1993 - 2012 England and Wales. 2013.

2. Rieder J, Gravier B, Bertrand D, Pasche C, Bodenmann P, Wolff H. Santé en milieu carceral Vulnerabilité partagée entre detenus et professionnels de la santé. Rev Med Suisse Romande. 2010;6:1462-5.

3. Wolff H, Sebo P, Haller DM, Eytan A, Niveau G, Bertrand D, et al. Health problems among detainees in Switzerland: a study using the ICPC-2 classification. BMC Public Health. 2011;11:245.

4. Rosen DL, Hammond WP, Wohl DA, Golin CE. Disease prevalence and use of health care among a national sample of black and white male state prisoners. J Health Care Poor Underserved. 2012;23(1):254-72.

5. Fazel S, Baillargeon J. The health of prisoners. Lancet. 2011;377(9769):956-65.

6. Fazel S, Bains P, Doll H. Substance abuse and dependence in prisoners: a systematic review. Addiction. 2006;101(2):181-91.

7. Wolff N, Frueh BC, Shi J, Gerardi D, Fabrikant N, Schumann BE. Trauma exposure and mental health characteristics of incarcerated females self-referred to specialty PTSD treatment. Psychiatr Serv. 2011;62(8):954-8.

8. Binswanger IA, Merrill JO, Krueger PM, White MC, Booth RE, Elmore JG. Gender differences in chronic medical, psychiatric, and substance-dependence disorders among jail inmates. Am J Public Health. 2010;100(3):476-82.

9. Parkes T, MacAskill S, Brooks O, Jepson R, Atherton I, Doi L, et al. Prison health needs assessment for alcohol problems. Edinburgh: NHS Health Scotland; 2011.

10. Kissell A, Taylor PJ, Walker J, Lewis E, Hammond A, Amos T. Disentangling alcohol-related needs among pre-trial prisoners: a longitudinal study. Alcohol and Alcoholism. 2014;49(6):639-644.

11. Etter JF, Ritter C, Christie DH, Kunz M, Rieder JP, Humair JP, et al. Implementation and impact of anti-smoking interventions in three prisons in the absence of appropriate legislation. Prev Med. 2012;55(5):475-81.

12. Ritter C, Huynh CK, Etter JF, Elger BS. Exposure to tobacco smoke before and after a partial smoking ban in prison: indoor air quality measures. Tob Control. 2012;21(5):488-91.

13. Clarke JG, Martin RA, Stein L, Lopes CE, Mello J, Friedmann P, et al. Working Inside for Smoking Elimination (Project W.I.S.E.) study design and rationale to prevent return to smoking after release from a smoke free prison. BMC Public Health. 2011;11:767 
14. Blaauw E, Roesch R, Kerkhof A. Mental disorders in European prison systems. Arrangements for mentally disordered prisoners in the prison systems of 13 European countries. Int J Law Psychiatry. 2000;23(5-6):649-63.

15. Fazel S, Seewald K. Severe mental illness in 33,588 prisoners worldwide: systematic review and meta-regression analysis. Br J Psychiatry. 2012;200(5):364-73.

16. Gisin D, Haller DM, Cerutti B, Wolff H, Bertrand D, Sebo P, et al. Mental health of young offenders in Switzerland: Recognizing psychiatric symptoms during detention. J Forensic Leg Med. 2012;19(6):332-6.

17. Wohl DA, Golin C, Rosen DL, May JM, White BL. Detection of undiagnosed HIV among state prison entrants. JAMA. 2013;310(20):2198-9.

18. Jurgens R, Nowak M, Day M. HIV and incarceration: prisons and detention. J Int AIDS Soc. 2011;14:26.

19. Dumont DM, Brockmann B, Dickman S, Alexander N, Rich JD. Public health and the epidemic of incarceration. Annu Rev Public Health. 2012;33:325-39

20. Semaille $C$, Le Strat $Y$, Chiron $E$, Chemlal $K$, Valantin MA, Serre $P$, et al. Prevalence of human immunodeficiency virus and hepatitis $C$ virus among French prison inmates in 2010: a challenge for public health policy. Euro Surveill. 2013;18(28). doi:10.2807/1560-7917.ES2013.18.28.20524.

21. Iten A, Gravier B, Brenner E, Khelifa A, Beer D, Duflon JP. Epidémiologie et prévention des infections dans les prisons de Suisse romande (EPIPS): deuxième phase de l'étude: rapport final, 1er novembre 2001-30 novembre 2005. Fonds national suisse de la recherche scientifique (FNS), Service de médecine et de psychiatrie pénitentiaires du canton de Vaud, Département de psychiatrie du CHUV, Lausanne, (3346-64170) 322 p., 2005. https:// serval.unil.ch/resource/serval:BIB_2951CD93FE79.P001/REF. Accessed September 2015.

22. Wilper AP, Woolhandler S, Boyd JW, Lasser KE, McCormick D, Bor DH, et al. The health and health care of US prisoners: results of a nationwide survey. Am J Public Health. 2009;99(4):666-72.

23. Walmsley R. World female imprisonment list. London: International centre for prison Studies; 2006.

24. Walmsley R. World prison population list. 2nd ed. London: Home Office Research, Development and Statistics Director-ate, 2000; 2000.

25. Williams BA, Goodwin JS, Baillargeon J, Ahalt C, Walter LC. Addressing the aging crisis in U.S. criminal justice health care. J Am Geriatr Soc. 2012;60(6):1150-6.

26. Hayes AJ, Burns A, Turnbull P, Shaw JJ. The health and social needs of older male prisoners. Int J Geriatr Psychiatry. 2012;27(11):1155-62.

27. Dawes J. Ageing Prisoners: issues for Social work. Aust Soc Work. 2009;62(2):258-71.

28. Loeb SJ, Abudagga A. Health-related research on older inmates: an integrative review. Res Nurs Health. 2006;29(6):556-65.

29. Williams BA, Stern MF, Mellow J, Safer M, Greifinger RB. Aging in correctional custody: setting a policy agenda for older prisoner health care. Am J Public Health. 2012;102(8):1475-81.

30. Macdonald M. Women prisoners, mental health, violence and abuse. Int J Law Psychiatry. 2013;36(3-4):293-303.

31. van den Bergh BJ, Gatherer A, Fraser A, Moller L. Imprisonment and women's health: concerns about gender sensitivity, human rights and public health. Bull World Health Organ. 2011;89(9):689-94.

32. World Health Organization WHO. Health in Prisons, A WHO guide to the essentials in prison health. 2007

33. Swiss Federal Statistical Office FSO. Privation de liberté, l'effectif de détenus au jour de relevé 1999-2013. 2014

34. Dauvergne M. Adult correctional statistics in Canada, 2010/2011. Statistics Canada. 2012. access website september 2015: http:// www.statcan.gc.ca/pub/85-002-x/2012001/article/11715-eng.htm

35. Académies Suisses des Sciences Médicales A. Exercice de la médecine auprès de personnes détenues - SAMW. Rapport des Académies Suisses des Sciences médicales 2002, updated 2012. http://www.samw.ch/fr/Ethique/ Exercice-de-la-medecine-carcerale.html. Accessed September 2015

36. Sprumont D, Schaffter G, Hostettler U, Richter M, Perrenoud J. Pratiques medicales de la médecine en milieu carcéral: Effectivité des directives de l'Académie suisse des sciences médiclaes sur l'exercice de la médecine aupres de personnes détenues. Document de travail, Université de Neuchatel, Faculté de droit, Institut de droit de la santé. 2009. www.unine.ch/ids/. Accessed August 2015.

37. World Health Organization WHO. International Classification of Diseases (ICD). 2014.
38. Carpentier C. Ten years of monitoring illicit drug use in prison population in Europe: issues and challenges. The Howard Journal of Crininal justice. 2011;51(1):37-66.

39. Gravier B, Benmebarek M. Enfermement et addictions : quelle place pour les soins? Dépendances. 2008:35:11-15.

40. Torrens M, Fonseca F, Castillo C, Domingo-Salvany A. Methadone maintenance treatment in Spain: the success of a harm reduction approach, Bulletin of the World Health Organization 2013;91:136-141. Bull World Health Organ. 2013;91:136-41.

41. Réseau canadien d'info-traitements sida C. Le VIH au canada Tendnaces et enjeux qui affectent la prevention du $\mathrm{VIH}$, les soins le traitement et le soutien. 2010.

42. Réseau juridique canadien $\mathrm{VIH} /$ sida; Redoubler d'efforts contre le sida et pour les droits humains. 2010;15(1). www.aidslaw.ca/revue. Accessed September 2015.

43. World Health Organization WHO. The global plan to stop TB 2006-2015. 2006.

44. Fazel S, Hope T, O'Donnell I, Jacoby R. Hidden psychiatric morbidity in elderly prisoners. Br J Psychiatry. 2001;179:535-9.

45. Fazel S, Hope T, O'Donnell I, Piper M, Jacoby R. Health of elderly male prisoners: worse than the general population, worse than younger prisoners. Age Ageing. 2001;30(5):403-7.

46. World Health Organization UNODC:. Good governance for prison health in the 21 st century. A policy brief on the organization of prison health. 2013.

47. Maschi T, Kwak J, Ko E, Morrissey MB. Forget me not: dementia in prison. Gerontologist. 2012;52(4):441-51.

48. Turner M, Payne S, Barbarachild Z. Care or custody? An evaluation of palliative care in prisons in North West England. Palliat Med. 2011;25(4):370-7.

49. Zurhold $\mathrm{H}$, Stöver $\mathrm{H}$, Haasen $\mathrm{C}$. Female drug users in European prisons Best practice for relapse prevention and reintegration. Hamburg: Centre for Interdisciplinary Addiction Research, University of Hamburg; 2004.

50. World Health Organization UNODC. Women's health in prison, Correcting gender inequity in prison health. 2009.

51. Rowan-Szal GA, Joe GW, Bartholomew NG, Pankow J, Simpson DD. Brief trauma and mental health assessments for female offenders in addiction treatment. J Offender Rehabil. 2012:51(1-2):57-77.

52. Newma WJ, Scott CL. Brown v. Plata: Overcrowding in California's prisons. J Am Acad Psychiatry Law. 2012;40:547-52.

53. Altice FL, Kamarulzaman A, Soriano W, Schechter M, Friedland GH. Treatment of medical, psychiatric, and substance-use comorbidities in people infected with HIV who use drugs. Lancet. 2010;376(9738):367-87.

54. World Health Organization WHO. Mental Health in Prisons, Headquarters and the International Committee of the Red Cross. 2005. Information Sheet.

55. Swiss Federal Statistical Office FS. Privation de liberté et exécution des sanctions - Données, indicateurs. 2013.

56. Swiss Federal Statistical Office FSO. Survol des maladies infectieuses. 2011.

57. Negro F. La lutte contre l'hépatite B et $C$ est une urgence pour la santé publique en Suisse. Bulletin des médecins suisses. 2013;94(27):1073-74.

58. Swiss Federal Statistical Office FSO. Prévalences de troubles physiques importants. 2011

59. Swiss Health Observatory OBSAN. Rapport de base sur la santé pour le canton de Vaud. 2014. Dossier 40

60. Bridevaux PO, Probst-Hensch NM, Schindler C, Curjuric I, Felber Dietrich D, Braendli $\mathrm{O}$, et al. Prevalence of airflow obstruction in smokers and neversmokers in Switzerland. Eur Respir J. 2010;36(6):1259-69.

61. Swiss Health Observatory OBSAN. La santé dans le canton de Vaud, Analyse des données de l'Enquête suisse sur la santé 2007. 2011. OBSAN RAPPORT 46. 